\title{
DEVELOPING COMPETENCY MODELS OF FACULTY DEVELOPERS
}

\author{
USING WORLD CAFE TO FOSTER DIALOGUE
}

\author{
Debra Dawson, The University of Western Ontario \\ Judy Britnell, Ryerson University
}

Alicia Hitchcock, The University of Western Ontario

Recent research by Chism (2007); Sorcinelli, Austin, Eddy, and Beach (2006); and Taylor (2005) speaks to the critical roles that faculty developers play in ensuring institutional success. Yet we have not as a profession identified the specific competencies necessary for success at different career stages. Our research generated these competencies for three faculty developer positions-entry-level, senior-level, and director-within a teaching and learning center. We used World Café, a collaborative discussion-based technique, to engage developers in building a matrix of competencies for each position and in determining how these competencies could be demonstrated.

The roles of faculty developers are rapidly evolving as teaching and learning centers grow in size, evolving from one-person operations to centers employing several developers (Sorcinelli, Austin, Eddy, \& Beach, 2006). Increasingly centers are being seen as central rather than peripheral to a university's success (Gosling, McDonald, \& Stockley, 2007; Harland \& Staniforth, 2008; McDonald \& Stockley, 2008). As Chism (2007) maintains, it is critical that we recruit new faculty developers and identify the skills and knowledge they require, given the worldwide expansion of university enrollment and the need for developers to facilitate change and innovation in higher education. However, the developer's roles must be 
clearly delineated for these centers to operate effectively. Furthermore, if we are to attract new members to our profession, we must identify the competencies necessary for success at different stages of the career.

In recent years, only a few scholars have researched how individuals enter our emerging profession (Gosling, 2001; McDonald \& Stockley, 2008). McDonald and Stockley (2008) found no clear pathway into the field of faculty development either in North America or internationally. Rather, they uncovered myriad ways in which individuals became faculty developers. They argued that, for the profession to continue to flourish, we need a clearer idea about why and how academics become involved in faculty development activities, what facilitates their progress, and whether they would choose this as their primary occupational identity. However, we surmise that part of the reason for the faculty developers' weak occupational identity may be that we have not yet clearly articulated the competencies necessary for success. As a result, some people believe that almost anyone can be a faculty developer and marginalize practitioners within the academy (Harland \& Staniforth, 2008).

Chism (2007) argues that, as an evolving profession, we have moved beyond an apprenticeship model of development and that we can now specify the skills and knowledge needed for entry. Her survey of more than 560 developers from around the world found that her respondents rated their content knowledge at entry to the profession as some to moderate for most categories, with the highest ratings going to knowledge of instructional design and active learning and the lowest to organizational change and faculty development. Both Taylor (2005) and Gosling et al. (2007) see faculty developers playing the role of change agents. Perhaps it is not surprising that those in entry-level positions know little about organizational change and do not see it as a necessary component of success for beginning faculty developers. Chism's research represents the most comprehensive overview of self-assessed skill and knowledge of faculty developers to date and makes a compelling argument for more formal career preparation. But her research does not differentiate skills, knowledge, and abilities of developers dependent on their role in the center; nor does earlier work by Wright and Miller (2000), which proposed fourteen action verbs to describe the developer's roles and responsibilities.

As centers grow in size, faculty developers may be expected to assume a variety of roles. This is exactly what Sorcinelli et al. (2006) found in both American and Canadian institutions, particularly research-doctoral or comprehensive universities. According to Wright (2002), campuswide centers typically have a director, associate director, faculty developers, 
and support staff. In this structure, each level requires its own skills, knowledge, abilities, and competencies.

The importance of clarifying these roles is underscored by the recent international research of Harland and Staniforth (2008), who reveal that faculty development may have many goals and vary dramatically from institution to institution in terms of the work. As some centers emphasize teaching and others research, the skills and expertise required of their employees may be quite disparate.

Our research on competencies focuses on identifying the knowledge, skills, abilities, and experiences that are demanded in three typical positions in faculty development centers, as well as demonstration of competency useful in assessing performance. According to the U.S. Department of Education, competency is "a combination of skills, abilities, and knowledge needed to perform a specific task" (U.S. Department of Education, 2002, p. 1, in Voorhees, 2001). Their competency model (see Figure 1.1) depicts the four levels that constitute a foundation for learning: traits and characteristics; skills, abilities, and knowledge; competencies; and finally demonstrations (for assessing the competencies through performance). Voorhees states that "each of the rungs of the ladder is thought to influence those rungs that appear above and underneath" (2001, p. 8). Ability can be understood as the individual's capacity to perform a task, and skills as expertise developed through practice or formal training or education. Traits constitute the innate make-up of individuals. Skills, abilities, and knowledge are acquired through many

Figure I.I. U.S. Department of Education Competency Model

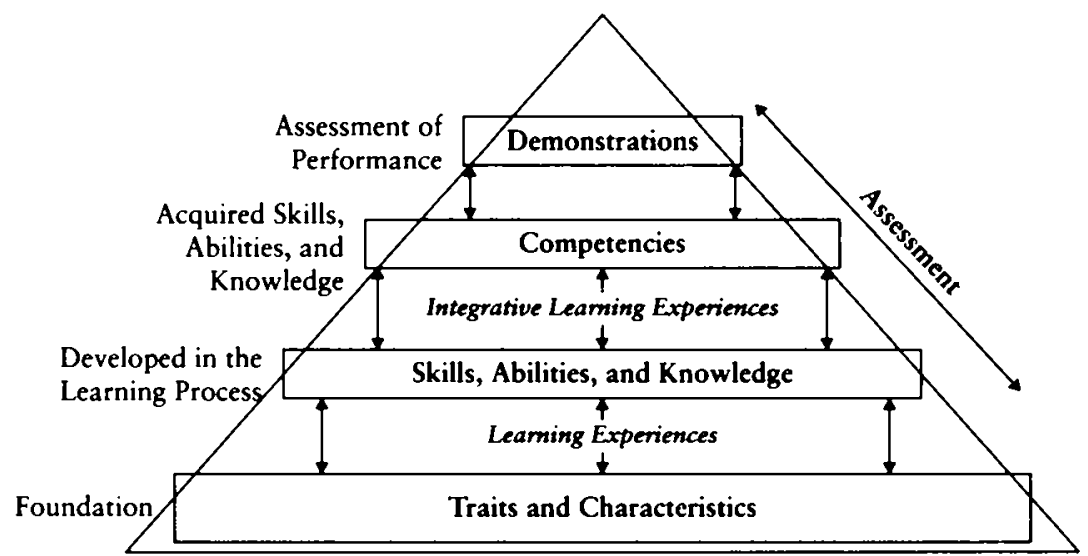

Source: U.S. Department of Education (2002); Voorhees (2001). 
learning experiences. Competencies result from integrative learning experiences within numerous contexts (Voorhees, 2001).

Given the many functions that faculty developers are expected to perform-from facilitating curriculum review to enhancing teaching and learning methods within an institution, to engaging in research on the scholarship of teaching and learning (Gosling, 2001; Harland \& Staniforth, 2008)-the required job competencies are problematic. The hierarchy of positions available in campuswide centers in research and comprehensive universities offers employees opportunities for career progression. This is a radical shift from a common past practice of appointing a teaching award winner as center director without recognition of the breadth of competencies required.

We believe we need to examine faculty developer roles now for two reasons. The first is to help centers expand and flourish. The second is to plan for succession during the wave of retirements we anticipate over the next decade. We need to facilitate the entry of new members into our profession. We focus here on identifying the competencies of three distinct faculty developer roles found in one type of center. We recognize that this center represents only the centralized model of faculty development and that the type of institution, its mission, and its culture all influence the nature and structure of a faculty development unit. But most of our results should extend across institutions.

\section{Research Methodology}

Like the work of Mullinix (2008), our research took "an active, constructivist approach" (p. 174) to gathering data on faculty developer competencies. We used World Café, a group work method, to facilitate discussion among our participants (Brown, 2005). Although World Café has not appeared in the literature as a research method, Heron and Reason (2001) point out that "good research is research conducted with people rather than on people" (p. 179). Cornwall and Jewkes (1995) refer to the distinctiveness of participatory research as being in the methodological context of how it is applied. The participants had a vested interest in the outcome of this work because of their affiliation with the issue being studied. Their experience also made them informants, so they were co-creators of the competency models. We have supported the notion of ownership of the findings by sharing the results of each session's discussions and the new models of representation with participants.

Our methodology differs from action research in that we, the researchers, are also affiliated with the topic being studied. However, consistent 
with action research, our intent was to find answers of major importance to the stakeholders, our participants. We also added cooperative inquiry into the process as a method used to inform practice (Heron \& Reason, 2001). In this case, faculty developers shared knowledge about common practice, thereby creating new knowledge. It is a process of creative action that can ultimately transform our practice.

\section{Phases to the Research}

Data were collected from several sources, including Internet listservs, a roundtable discussion, and three additional discussions guided by the principles of World Café that involved faculty developers in the data analysis and interpretation. In the first stage of the research, we reviewed twenty-five short descriptions of faculty developer positions that had been gathered electronically from Canadian faculty development listservs between 2002 and 2008. All of the job descriptions were from researchintensive or comprehensive universities of middle to large size (more than fourteen thousand students, with some graduate students). We eliminated positions that focused on technology (for instance, instructional designers) or that were discipline-specific (such as a teaching and learning center for a medical school). The descriptions fell into three position categories: director of a teaching and learning center $(\mathrm{N}=10)$, associate director/ senior faculty developer $(N=8)$, and entry-level faculty developer $(N=7)$. We distilled the common responsibilities and typical activities for each position type. These three generic job descriptions are presented in the Appendix.

In the second phase of the research, we determined how we would collect data from as many faculty developers as possible, selecting World Café as the best way to engage many participants in a purposeful, collaborative dialogue (Brown, 2005). The method relies on a café-like atmosphere created with round tables, tablecloths, music, and food. Each table has up to six participants and a table host who stays at her table when a new group of participants joins her in the second or third round of conversation. She also summarizes each group's ten-to-fifteenminute conversation. In this welcoming setting, each participant "has the opportunity to share what is true and meaningful" (Cunningham, 2007, p. 4). In addition to creating a hospitable environment, World Café is premised on exploring questions that matter; encouraging everyone's contribution; connecting diverse people and ideas; listening for insights, patterns, and deeper questions; and making collective knowledge visible (Brown, 2005). 


\section{Findings}

Our data collection process was an iterative one in which previous sessions guided later ones, so we will present the findings for each session. We held four data-gathering sessions during 2008 , at four faculty development conferences. The participants were self-selected. The first, third, and fourth sessions followed the World Café model, while the second session was a roundtable discussion. All participants granted us explicit permission to include their work (the competency models) in our research.

\section{Session One}

During a national Canadian conference (Educational Developers Caucus 2008), fourteen faculty developers participated in a ninety-minute groupwork session using World Café. First, we reviewed the competency development model of the U.S. Department of Education and the rules of World Café (World Café, 2008), fielding the questions that arose. Participants then dispersed among three tables, where they were to read one of the generic job descriptions and address these questions:

- What are competencies necessary for individuals to succeed in this position?

- How would they acquire them?

- What questions do you want the next group to consider?

Each table selected a table host to facilitate the discussion and stay at the table for all three rounds of discussion. Participants were given markers and a large piece of paper for writing key words and developing a competency model for each position. Because this was World Café, participants had candy and cookies to eat during the sessions and were encouraged to work collaboratively. After fifteen minutes, they moved individually to new tables (rather than as a group) for the next discussion round in order to maximize opportunities for unique contributions to the models. After three rounds, the table hosts presented their model to the whole group, which then identified differences among the models and raised questions to refer to an international group of developers, who would assess the models for their global validity (session two). As researchers, we answered participants' questions but did not contribute to their development of the competency models.

This first session generated dramatically different models for each of the three faculty developer positions. As shown in Figure 1.2, the director's model emphasized three perceived roles, which the participants 
Figure r.2. Competency Model for the Director of a Faculty Development Center from Session One

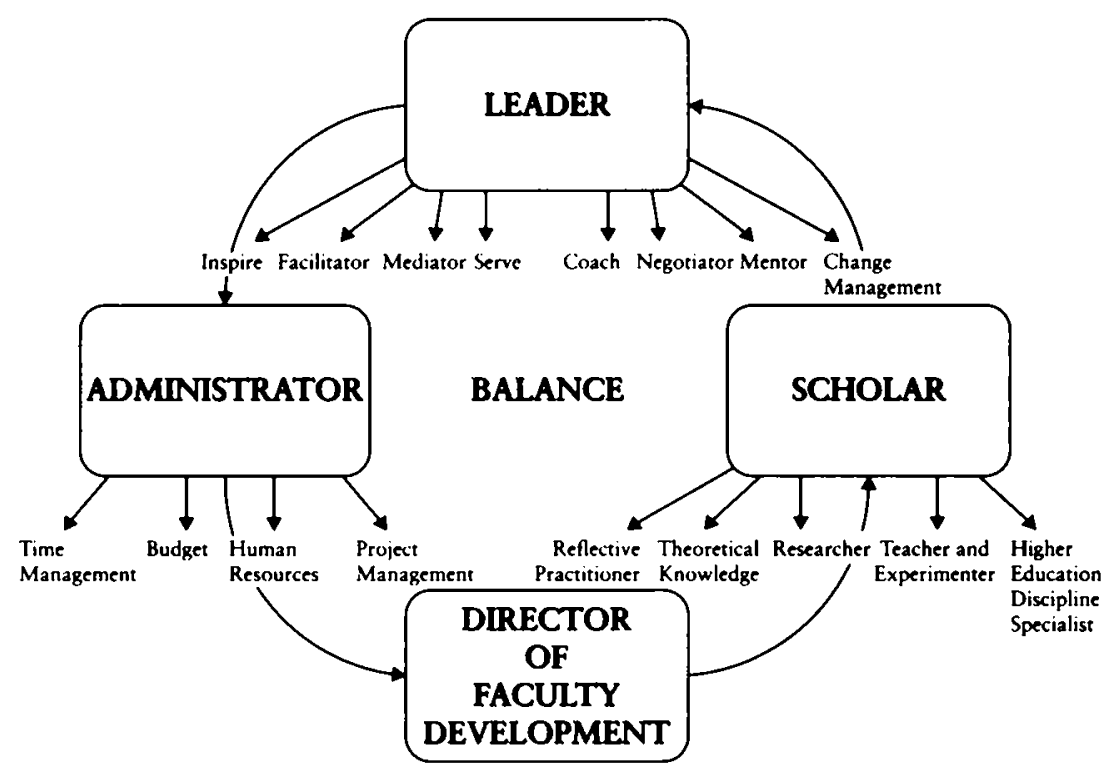

defined as leader, administrator, and scholar. For each role they also delineated several competencies, traits, and skills. Their model included as well a pathway between the roles and key word "balance" in the center of the diagram. For the entry-level position, depicted in Figure 1.3, the participants focused on all levels of the competency model (from traits to competencies) but emphasized traits and characteristics. In fact, the participants agreed that entry-level positions required incumbents with certain traits and that skills and abilities could be acquired later with training. The model for the senior faculty developer position, shown in Figure 1.4, placed high importance on the abilities the individual had developed and listed fewer competencies than the director's model.

\section{Session Two}

The next session was a sixty-minute roundtable discussion among seven faculty development experts attending an international conference (International Consortium of Educational Development 2008). The participants were asked to review the competency model of the U.S. Department of Education and then use it as a tool for analysis of the three group-developed models. They also reviewed the position descriptions. 


\section{Figure 1.3. Competency Model for the Entry-Level Faculty Developer Position from Session One}

Traits and Characteristics

Comfortable with a Wide Range of

Technology

Can Work Collaboratively

Development of a Teaching

Philosophy

Team Player

Self-Awareness

Passion and Commitment

Patience and Persistence

Leadership Abilities

Manage

Mediate

Serve

Inspire

Facilitate

Negotiate

Mentor

Coach

Skills

Facilitate Workshops

Research Skills

Outreach and Marketing Skills

Teaching Skills

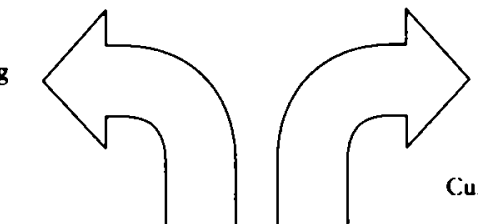

Information Technology
um Development Theory

Workplace Learning

Self-Awareness

Reflective Practice

Mentoring and Coaching

Administration

Institutional Fit

Competencies

Planning and Implementing Projects

(Project Management)

Program Evaluation

Effective Consulter

Communicates Effectively

Development of Resources

Their primary tasks were to identify gaps in the group-developed models and ensure their broad cultural applicability. For each model, the participants expanded the lists of required skills, traits, knowledge, abilities, and competencies, generating such lengthy lists that we wondered if all the additions were equally valued. Fortunately, our participants suggested that we use the third session for ranking the top three traits, skills, knowledge, abilities, and competencies.

\section{Session Three}

This seventy-five-minute session was held at an international conference of faculty developers (Professional and Organizational Development Network in Higher Education 2008). We again returned to the World Café methodology, including colorful tablecloths and candy. As in session one, we first described the World Café process, reviewed the U.S. Department of Education competency model, and then asked our nineteen participants to review, in light of the original job descriptions, the competency models developed in session two. As in the first session, they had fifteen minutes 


\section{Figure 1.4. Competency Model for the Senior Faculty Developer from Session One}

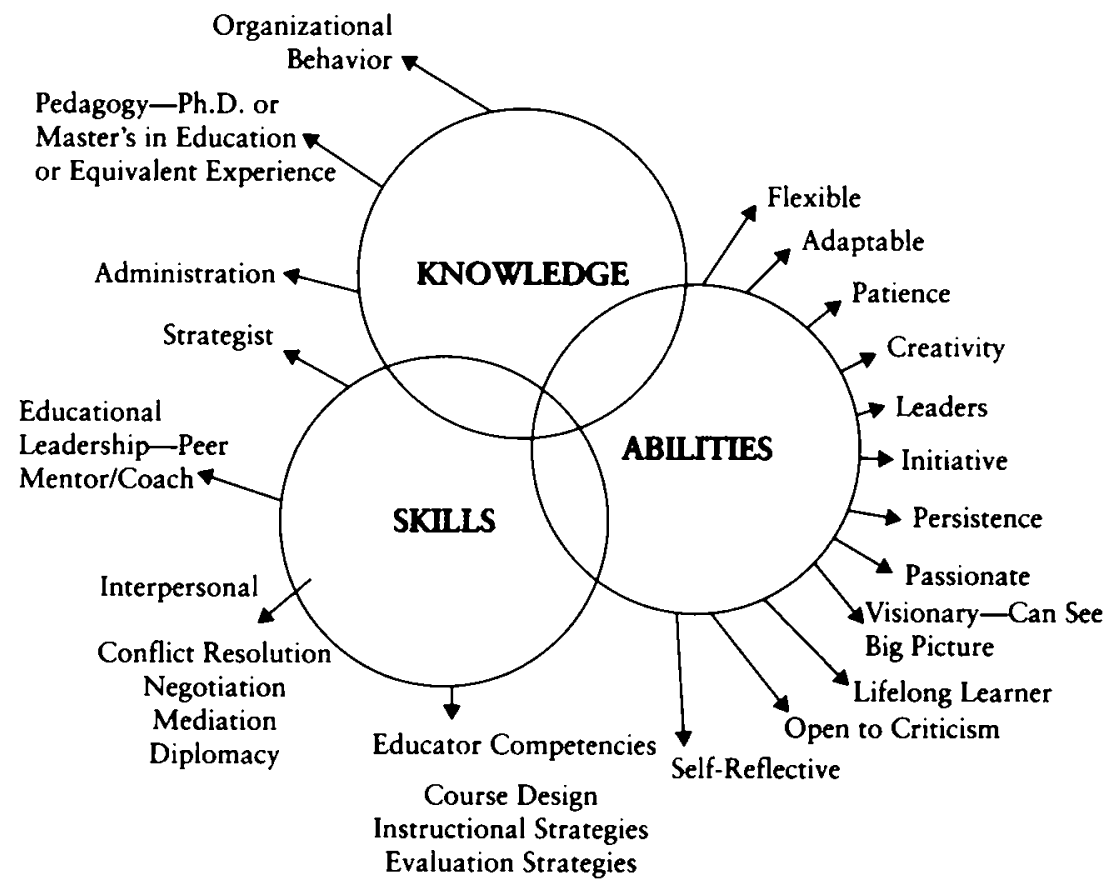

for each round to explore one of the models. In addition to identifying any gaps or omissions, they were asked to rank the three most important skills, abilities, knowledge, competencies, and traits for each model.

Table 1.1 displays these rankings. A score of ten or higher designates the items that the participants perceived to be most important. For the entrylevel position, it was most important to be a team player, exhibit reflective practice, communicate effectively, and have strong learning skills, knowledge of curriculum development theory, and leadership abilities in the area of facilitation. For the senior faculty developer, the most important trait was being passionate about faculty development, followed by strong interpersonal skills in working with others. In addition, the successful incumbent would demonstrate educational leadership, have formal graduate education in pedagogy, possess strong competencies as an educator, and be able to develop and implement programs. For the director's position, skill at balancing the three roles became paramount, making time management skills critical, along with competencies in facilitation, advocacy, and change management. The role of leader also within the institution gained prominence. 


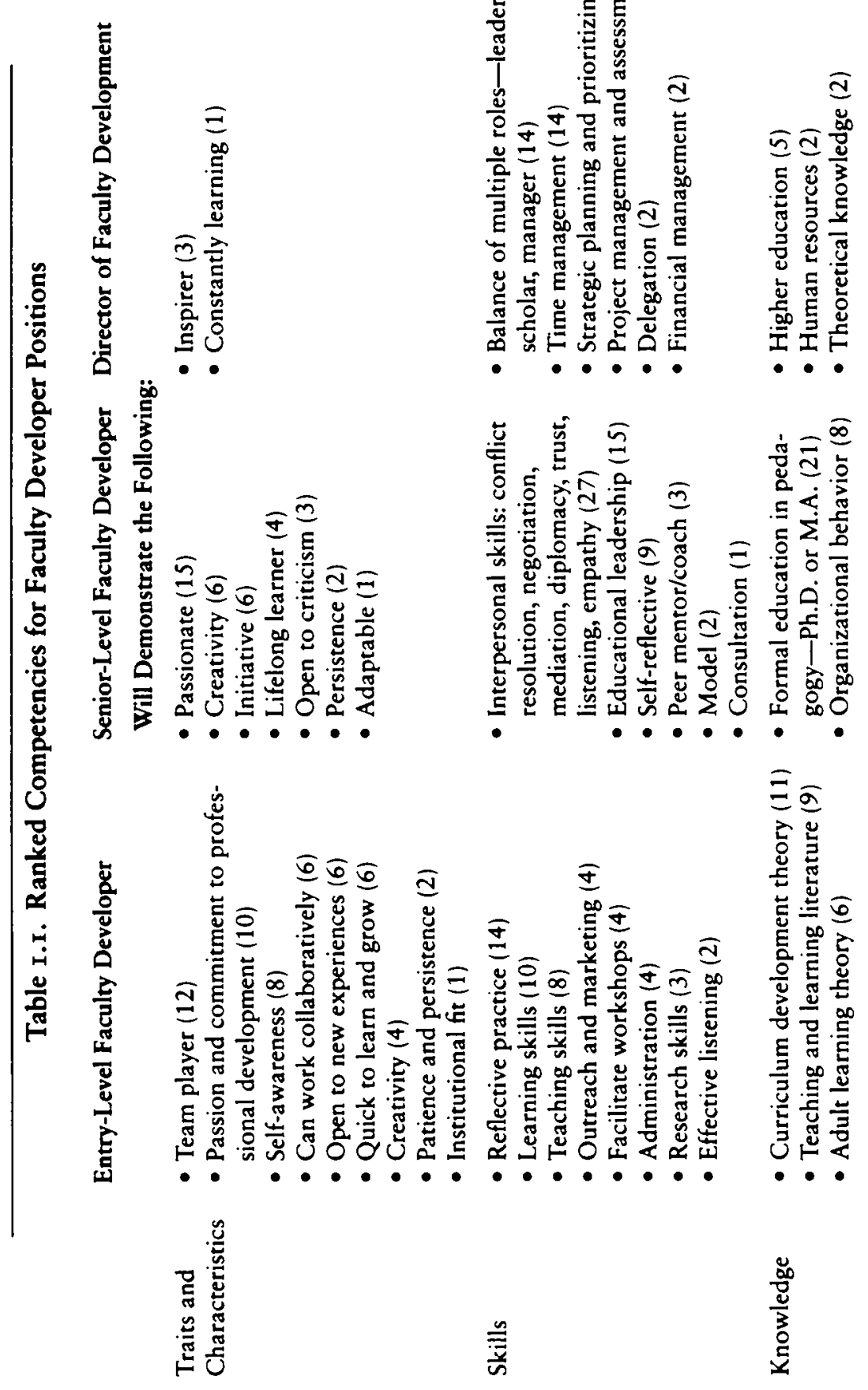



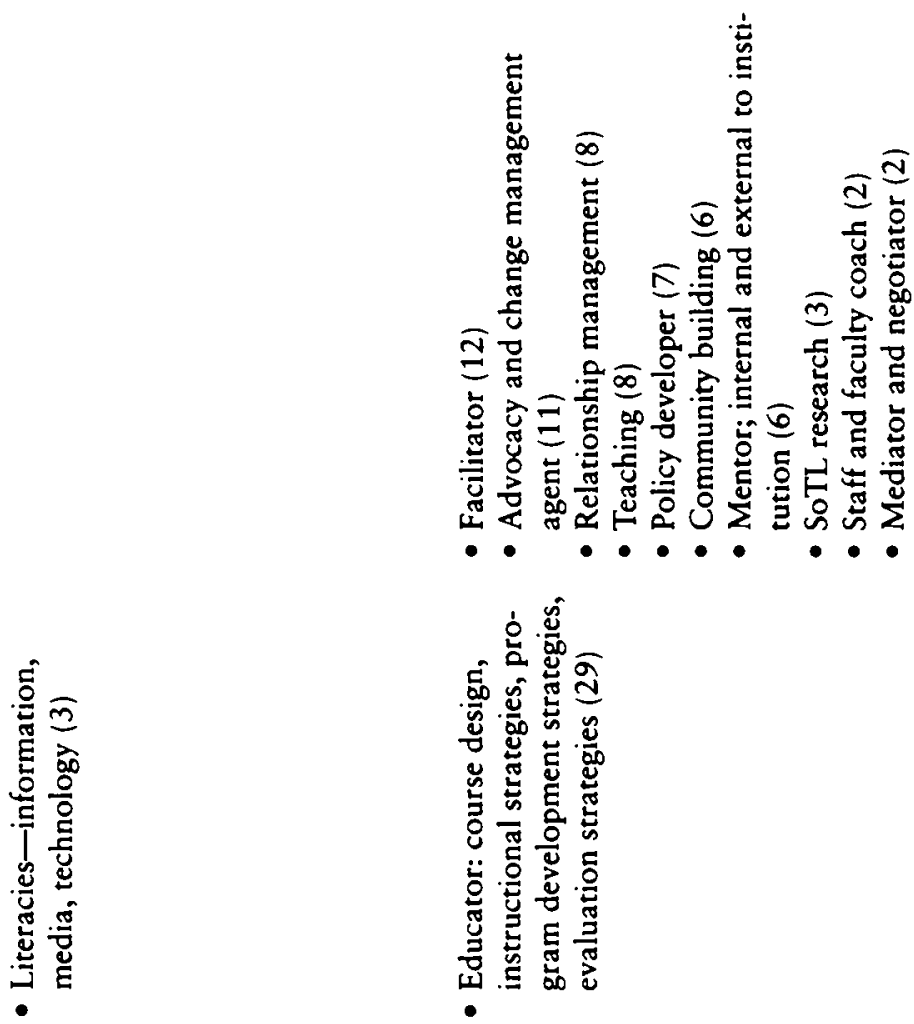

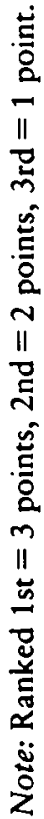

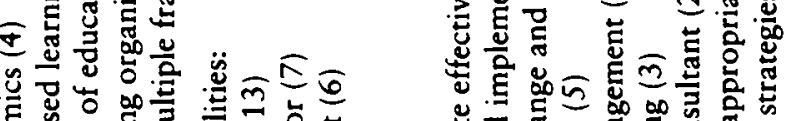

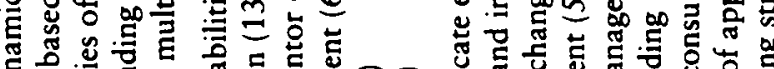

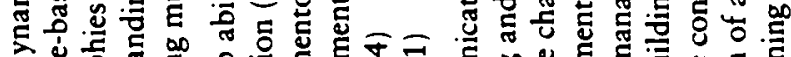

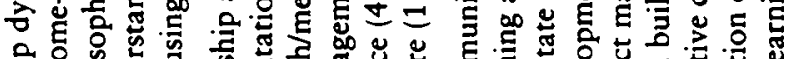

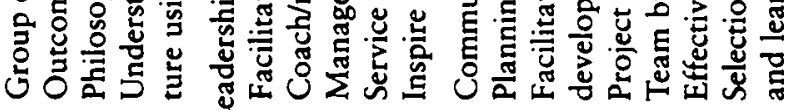

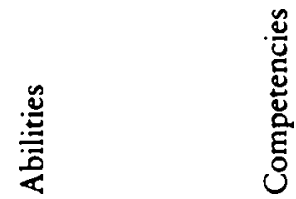


The participants suggested that they would find it easier to detect gaps in the models if all of them looked like the competency model developed by the U.S. Department of Education as presented in Figure 1.1.

\section{Session Four}

For our fourth and final session, we reformatted the information in Table 1.1 into the models presented in Figures 1.5, 1.6, and 1.7. Twenty Canadian faculty developers and one international developer participated in this final ninety-minute World Café session (Council of Ontario Educational Developers 2008), complete with refreshments and background music. As in sessions one and three, we first described World Café, reviewed the U.S. Department of Education competency model, and then asked our participants to review, in light of the original job descriptions, the competency models developed thus far. At the first fifteen-minute round of discussions, participants were asked to identify large gaps in the traits and characteristics, skills, abilities, knowledge, and competency levels. During the second and third rounds, they were to decide, beyond the position description given, how they would expect an individual to demonstrate that he or she had achieved these competencies.

Participants developed a variety of demonstrations of competence, all listed in Table 1.2. To document reflective practice (a skill seen as especially essential for the senior faculty developer and director's positions), they recommended a portfolio. For the entry-level position, they favored the performance feedback of peers and faculty. Finally, at the director's level an incumbent must demonstrate competence in strategic planning and implementation, which requires documentation as well as integration of sound management principles.

Session four's discussions raised problematic issues and questions. How can one assess resilience, tolerance for uncertainty, and rapport and effectiveness in confidential interactions with clients-all critical competencies for the entry-level position? Is teaching experience or formal education in pedagogy more important at the senior faculty developer level? The answer may be context- or institution-dependent. Some participants believed that a director should be capable of doing the work of the other two positions, which meant having many of their traits, skills, knowledge, and competencies. Perhaps our participants required fewer traits, characteristics, abilities, and knowledge of the highest-level position (see Table 1.2) because they assumed the director would have many of them already. The session four participants identified integrity, a sense of agency, being a people person, and responsiveness as crucial director 


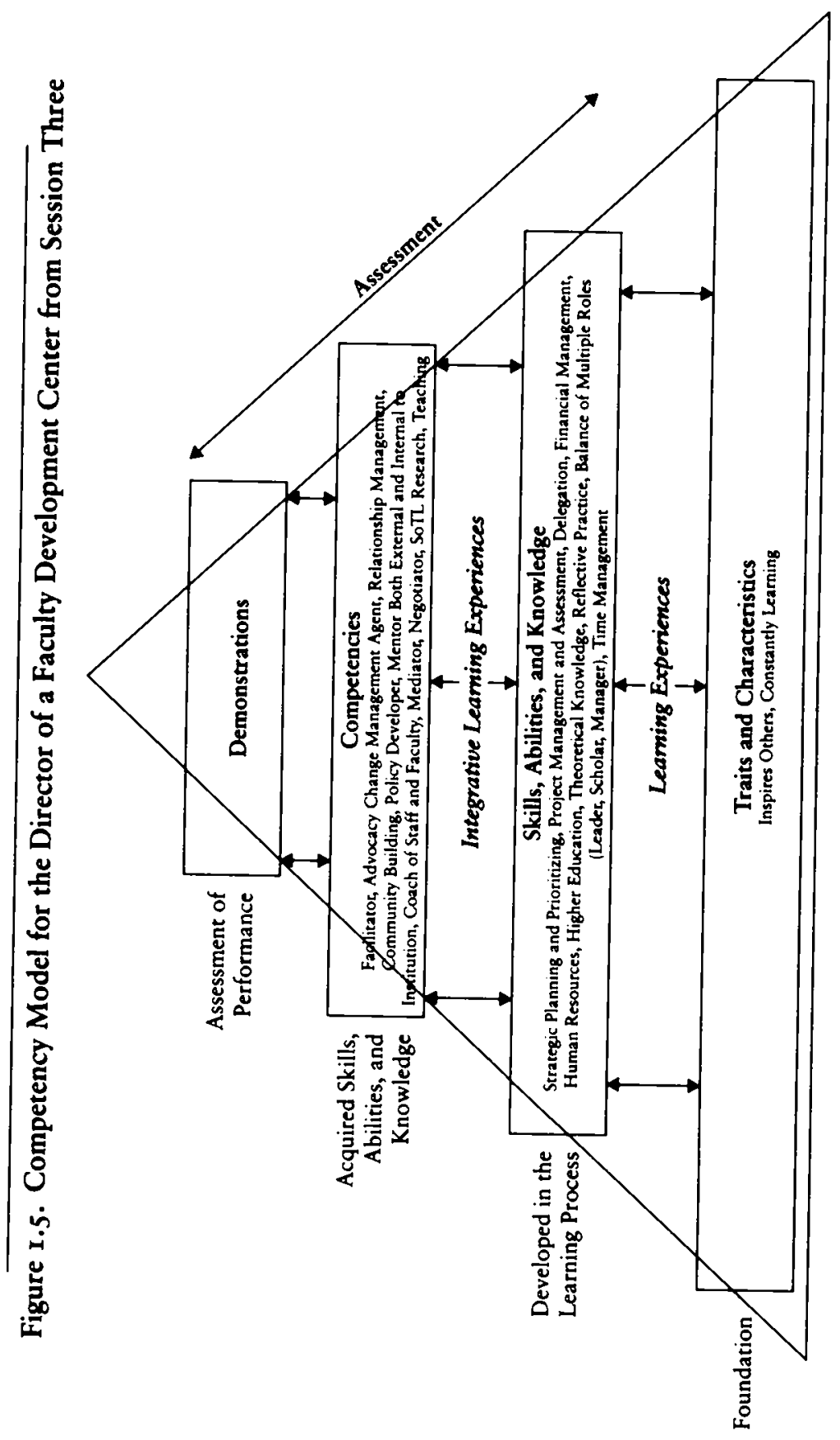




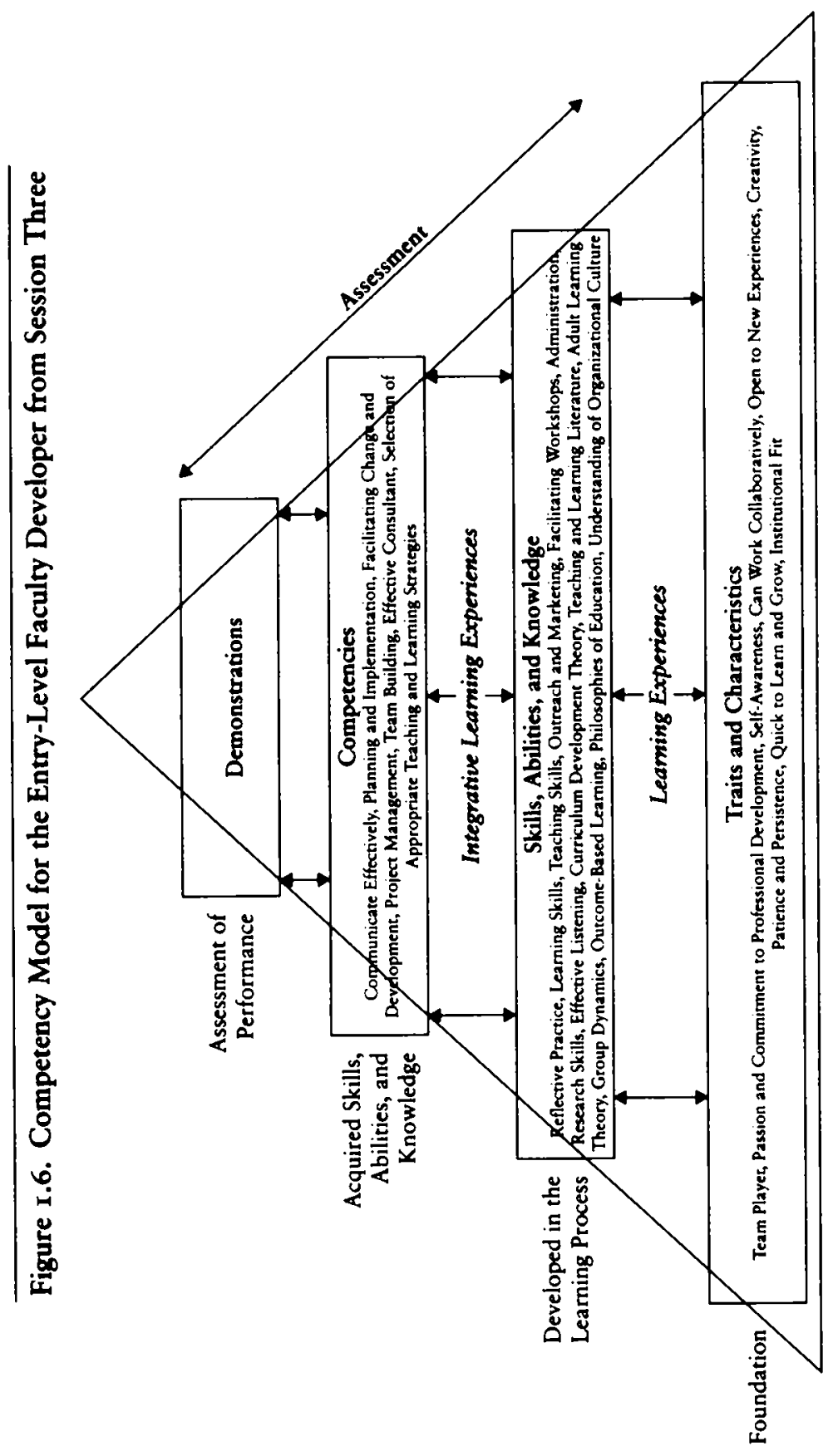




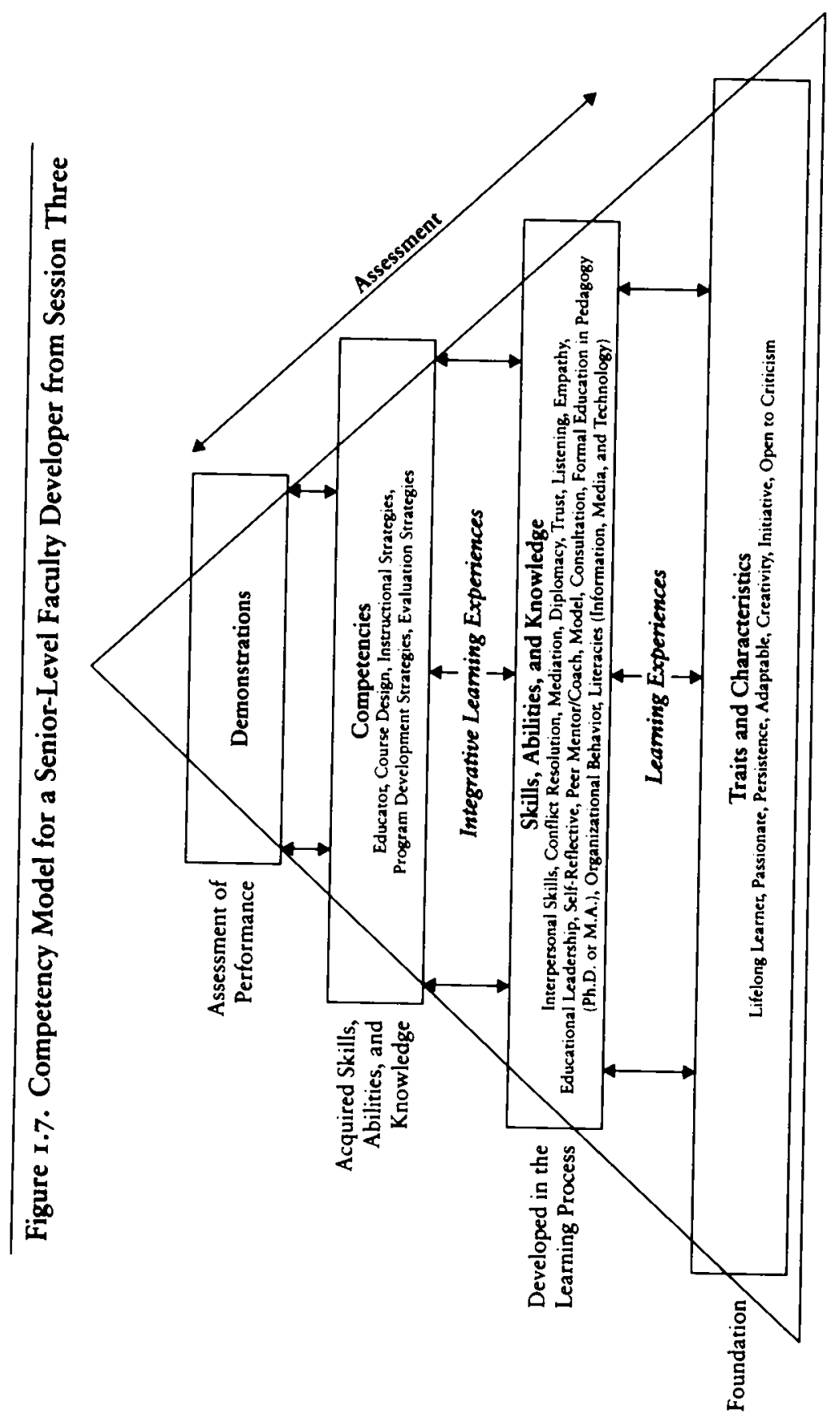




\title{
Table 1.2. Demonstration of Competency for Faculty Developer Positions
}

\author{
Position \\ Demonstration of Competencies \\ Director of faculty \\ development center \\ - Show evidence of self-reflection and strategies practice \\ through a director's portfolio \\ - Evidence of the ability to respectfully manage relation- \\ ships with staff, faculty, and administration \\ - Visible strategic plan and alignment with the universi- \\ ty's strategic plan \\ - Staff satisfaction as evidenced by low turnover rate \\ - Qualitative artifacts \\ - Performance plan with stated goals and evidence of \\ performance \\ Senior-level faculty \\ developer position \\ - Portfolio of reflective practice such as a teaching \\ portfolio \\ - Evidence of improvement in teaching development \\ - Show evidence of ability to operate programs effec- \\ tively and with good outcomes (participant evalua- \\ tions) \\ - Show evidence of program growth \\ - Demonstrate competencies through establishing goals/ \\ objectives and assessment \\ - Demonstrate cultural competency \\ - Show evidence of ability to work well with various \\ campus groups \\ Entry-level faculty \\ - Presentations with formal peer assessment \\ developer position \\ - Feedback from faculty after consultation (interviews, \\ evaluation forms) \\ - Evidence of commitment to learning such as seeking \\ mentorship, participation in educational programs \\ - New programs initiated and sustained and the ability \\ to redevelop existing programs \\ - Teaching experience in relevant environment
}

traits. They also recommended assessing the values and attitudes of individuals for all three of these positions.

\section{Discussion}

Our research involving experienced faculty developers allowed multiple voices to be heard, which we believe enhanced the quality and depth of the competency models created. Using World Café as our research method-although this is uncommon-generated a richer discussion over 
less time than traditional discussion techniques or surveys could have accomplished. Because it maximized inclusion, this form of participatory action research was well suited to developing the three competency models (Kemmis \& McTaggart, 2005). Each session we held validated and elaborated the models. Adding the voices of multiple global experts ensured broad cultural representation.

Our results delineate three distinctive competency sets necessary for success at the stages of a faculty developer's career. Those specifically from session three recommend that entry-level faculty developers be hired largely on the traits they possess, such as creativity, and a few competencies, such as project management. Senior faculty developers, on the other hand, require more fully developed interpersonal and leadership skills. At the director level, the needed competencies are much more complex: change management, facilitation, relationship management, and policy development. In contrast to Wright and Miller's study (2000), our participants speculated that directors are assuming the new role of change agent, which expands the position to advocate, policy developer, and change manager. Both Chism (2007) and Sorcinelli et al. (2006) emphasize this emerging role of developers as change agents.

Our session four participants outlined several ways to demonstrate faculty developer competencies, from peer performance review to developers' portfolios. Interestingly, Wright and Miller (2000) recommended some time ago that developers use such a portfolio to document their accomplishments. The portfolio would resemble a teaching portfolio, with a section on faculty development responsibilities and a philosophy statement. It would generate critical documentation for developers at all levels.

\section{Conclusion}

The faculty development profession is emerging, so we expect the role to change and evolve within our institutions. Arreola, Theall, and Aleamoni (2003) conceptualize that the role of faculty now must encompass disciplinespecific skills and knowledge plus metaprofessional skills related to teaching, service, administration, and creative activities. Therefore, the competencies required for developers will need to expand accordingly.

In their discussion of the current "age of the network," Sorcinelli et al. (2006) posit that the rising expectations of students, faculty, and institutions are pushing the developer role toward greater complexity. They suggest that the function may move beyond institutional leader to leadership developer of new administrators. If they are correct, one or more faculty development positions will take on yet another new required competency. 
Many questions about our practice raised by our participants remain to be answered:

- How well do these competency models reflect the requirements of these faculty development positions across institutional settings?

- Given different cultural perspectives on their work, how do faculty developers weigh abilities, skills, knowledge, traits, and competencies in hiring for these positions?

- As values and attitudes are seen as the human and social capital needed for the positions, what roles do they play in shaping traits and characteristics?

- What are those values and attitudes?

Defining competencies is a first step in creating the faculty developer's occupational identity, and only continuing dialogue among developers can further validate these models. We are grateful to the sixty contributors who participated in the process thus far. If these models prove viable, we must ensure that developers have the opportunities to develop the competencies identified. Without a clear career path, individuals may find it difficult to anticipate and acquire the competencies necessary for career progression. We hope this line of research will support the diverse work of developers and enhance the credibility of their work worldwide. These models should also help clarify the roles that faculty developers can play in advancing institutional missions and mandates.

\section{Appendix A: Faculty Developer Job Descriptions Entry-Level Faculty Developer}

\section{Overview of Responsibilities}

- Participates in development, planning, implementation, and evaluation of both new and ongoing programs to support teaching and learning excellence at the university

- Under the direction of the director or senior faculty developer, collaborates with the faculties and academic units to offer discipline-specific programs as well as instruction in centralized programs offered through the teaching and learning center

- Identifies and develops opportunities for teaching project collaboration between the faculties and the teaching and learning center

- Collaborates with faculty on research related to the scholarship of teaching in various disciplines 
- Promotes and supports activities and events that concern the university community on teaching and learning issues

\section{Specific Activities}

- Conducts workshops and other programs both in the center and in specific faculties on request (this will take up to 60 percent of the individual's time)

- Supports departmental teaching programs through consultations, facilitation, and workshop development

- Develops and updates the center's website content

- Identifies and creates teaching and learning resources

- Performs administrative duties related to faculty programming, including preparation of reports, scheduling, and advertising

- Assists the senior faculty developer in designing and implementing new programs

- Edits the center's newsletter

- Conducts research on the scholarship of teaching

- Offers a leadership role on specific projects

\section{Associate Director/Senior Faculty Developer}

\section{Overview of Responsibilities}

- Reports to the director

- Performs confidential consultations with faculty, graduate students, and academic units on teaching and learning issues

- Develops and implements educational programs and activities

- Facilitates curriculum development and evaluation

- Conducts and disseminates research on teaching and learning

\section{Specific Activities}

- Takes the lead on one of the center's programs, such as the graduate education initiative; develops, implements, and administers a universitywide program to support graduate student education, to include both TA training and development of other competencies related to graduate student success (for example, academic and nonacademic career preparation and advanced presentation skills) 
- Plans, facilitates, and implements workshops within the center as well as educational development sessions in specific departments when requested

- Takes a leadership role in coordinating one of the center's initiatives such as new faculty orientation

- Contributes to development of print and Web-based teaching and learning resources and is expected to contribute to the field of faculty development through conducting research related to teaching and learning

- Supports faculty in their scholarship of teaching and learning

- May teach in the graduate course Theory and Practice of University Teaching

- May sit on university committees related to teaching and learning

- Aids in preparation of budgets, plans, and reports

- Collaborates with the director and staff to plan, coordinate, implement, and evaluate a variety of programs and activities to support teaching and learning at all levels

- Establishes and maintains effective networks with the regional, national, and international faculty development communities

\section{Director of Faculty Development Center}

\section{Overview of Responsibilities}

- Supervises the work of the other staff and reports to the academic VP

- Exercises leadership in visioning, planning, developing, and administering educational development programs

- Works collaboratively with the faculty of graduate studies and the university's academic and administrative units to support and advance teaching and learning initiatives on campus

- Plays an active role in research on the scholarship of teaching and learning

- Actively participates and where possible takes a leadership role in national and international associations dealing with educational development issues

- Controls the unit's budget 


\section{Specific Activities}

- Consults with faculty, academic administrators, and academic units on learning and teaching issues

- Oversees development and implementation of specific educational development programs for faculty, graduate students, and postdocs

- Fosters, conducts, synthesizes, and disseminates research on teaching and learning

- Performs confidential consultations with faculty, deans, and chairs on curriculum design and strategies to enhance teaching and learning within the university

- Networks to further advance the role of faculty development in higher education

- Sits on policy-making committees related to teaching and learning within the university

- Participates on the teaching awards committee

- Coordinates the graduate course Theory and Practice of University Teaching

- Oversees the budget planning of the unit

\section{REFERENCES}

Arreola, R. A., Theall, M., \& Aleamoni, L. M. (2003). Beyond scholarship: Recognizing the multiple roles of the professoriate. Paper presented at the 83rd annual meeting of the American Educational Research Association, Chicago.

Brown, J. (2005). The World Café: Shaping our futures through conversations that matter. San Francisco: Berrett-Koehler.

Chism, N.V.N. (2007, October). A professional priority: Preparing future developers. Paper presented at the 32nd annual meeting of the Professional and Organizational Development Network in Higher Education, Pittsburgh, PA.

Cornwall, A., \& Jewkes, R. (1995). What is participatory research? Social Science and Medicine, 41(12), 1667-1676.

Cunningham, S. (2007). Reflections of an innovative teaching or group-work method: The World Café. STLHE Teaching and Learning in Higher Education, 47, 4-5.

Gosling, D. (2001). Educational development units in the UK: What are they doing five years on? International Journal for Academic Development, 6(1), 74-90.

Gosling, D., McDonald, J., \& Stockley, D. (2007). We did it our way! Narratives of pathways to the profession of educational development. Educational Developments, 8(4), 1-5. 
Harland, T., \& Staniforth, D. (2008). A family of strangers: The fragmented nature of academic development. Teaching in Higher Education, 13(6), 669-678.

Heron, J., \& Reason, P. (2001). The practice of co-operative inquiry: Research with rather than on people. In P. Reason \& H. Bradbury (Eds.), Handbook of action research: Participative inquiry and practice (pp. 179-188). London: Sage.

Kemmis, S., \& McTaggart, R. (2005). Participatory action research: Communicative action and the public sphere. In N. K. Denzin \& Y. S. Lincoln (Eds.), Handbook of qualitative research (3rd ed., pp. 559-604). Thousand Oaks, CA: Sage.

McDonald, J., \& Stockley, D. (2008). Pathways to the profession of educational development: An international perspective. International Journal for Academic Development, 13(3), 213-218.

Mullinix, B. (2008). Credibility and effectiveness in context: An exploration of the importance of faculty status for faculty developers. In D. R. Robertson \& L. B. Nilson (Eds.), To improve the academy: Vol. 26. Resources for faculty, instructional, and organizational development (pp. 173-195). San Francisco: Jossey-Bass.

Sorcinelli, M. D., Austin, A. E., Eddy, P. L., \& Beach, A. L. (2006). Creating the future of faculty development: Learning from the past, understanding the present. Bolton, MA: Anker.

Taylor, K. L. (2005). Academic development as institutional leadership: An interplay of person, role, strategy, and institution. International Journal for Academic Development, 10(1), 31-46.

U.S. Department of Education, National Center for Education Statistics. (2002). Defining and assessing learning: Exploring competency-based initiatives (NCES 2002-159). Prepared by Elizabeth A. Jones and Richard A. Voorhees, with Karen Paulson, for the Council of the National Postsecondary Education Cooperative Working Group on CompetencyBased Initiatives. Washington, DC: Author.

Voorhees, R. A. (2001). Competency-based learning models: A necessary future. In R. A. Voorhees (Ed.), New directions for institutional research: No. 110. Measuring what matters: Competency-based learning models in higher education (pp. 5-13). San Francisco: Jossey-Bass.

World Café. (2008). The World Café presents café to go: A quick reference guide for putting conversation to work. Retrieved February 14, 2008, from www.theworldcafe.com/articles/cafetogo.pdf

Wright, A., \& Miller, J. (2000). The educational developer's portfolio. International Journal for Academic Development, S(1), 20-29.

Wright, D. L. (2002). Program types and prototypes. In K. H. Gillespie, L. R. Hilsen, \& E. C. Wadsworth (Eds.), A guide to faculty development: Practical advice, examples, and resources (pp. 24-34). Bolton, MA: Anker. 